\title{
Medicine and Public Health in China Today
}

\author{
WILLIAM Y. CHEN, M.D., M.P.H.
}

SINCE CHINA is a great country with a $D$ population of more than 600 million and a territory as big as the United States, its accomplishments in medicine and public health during the last 10 years are worthy of study. To cope with the demand of national industrialization and reconstruction, much attention has been paid to public health and medicine in an effort to prevent disease and promote health and thus increase productivity. Since public health practice is closely related to political systems and governmental structures, in addition to indicating actual achievements, it serves as an indirect reflection of the political and socioeconomic status of present-day China.

The main sources of the information in this article are various medical and public health journals published in Chinese and English during the past 10 years. The Chinese Medical Journal of the Chinese Medical Association has a complete English edition. Also, many journals of the various medical specialties print English abstracts. English translations of scattered articles from original Chinese medical publications have been published by the U.S. Department of Commerce in the past 2 years. They are valuable to scientists interested in the details of research in specific fields.

It is the primary intention of the author to evaluate critically achievements in medicine

Dr. Chen is medical officer in charge of the Environmental Cancer Field Research Center, National Institutes of Health, Public Health Service, Hagerstown, Md. One portion of a symposium, "Sciences in Communist China," held in New York City last December, this paper by Dr. Chen is printed here with permission of the sponsors, the American Association for the Advancement of Science. The full proceedings of the symposium were published by the association in June 1961. and public health in China during the past decade rather than review the literature. Also, I will emphasize achievements and new developments unfamiliar to the Western World and the future trends of medicine and public health in China. Most Chinese and English language publications issued in China have been reviewed as well as reports from nonChinese sources.

\section{Conditions in Pre-Communist China}

To understand medicine and public health in China today, it will be helpful to examine briefly the situation in these fields in preCommunist China.

Before the Communist regime took control in 1949, medicine and public health were far below modern standards. Poverty was widespread and diseases raged the country. For example, the general mortality rate in Peking was as high as 14.1 per 1,000 . More than 75 percent of the population was illiterate. The total number of scientifically trained physicians was estimated to be 12,000 in about 500 hospitals; the country's medical schools were capable of producing only 500 graduates per year for an estimated population of 400 million.

In "China's Health Problems," published in 1944, Sze (1) described China's plans to combat the excessive mortality of 4 million a year caused by infectious and parasitic diseases and to provide the necessary facilities for the daily treatment of about 60 million patients. Because 84 percent of the total population in the rural areas was incapable of paying for private medical care, the only early solution was believed to be a system of state or socialized medicine as planned by $\mathrm{Lim}$ and Chen (2). As early as 1939 a new Hsien or county health center system was started, and by the end 
of World War II, there were some 1,775 county health centers, 26 provincial medical centers, 125 provincial hospitals, and 307 missionary and other private hospitals. There were 15 national, 5 provincial, and 10 private medical colleges, 5 pharmacological schools, 3 dental schools, 22 midwifery schools, and 317 nursing schools. The county health center is comparable to the county health department in the United States, but preventive medicine, public health, and medical care are combined under one governmental authority differing from the U.S. system. Generally, its functions are general administration, medical care, epidemic prevention, environmental sanitation, maternal and child health, health education, and vital statistics.

China was more unified organizationally after V-J Day, and a centralized national government exercised its authority over health matters in all Provinces more strongly than before. The county health center system was planned, shaped, and conducted mostly by U.S.-trained physicians; many of them still live in China and, in fact form the backbone of China's medical and health structure.

In "Western Medicine in Pre-Communist China" (3) Grant gives a brief but precise history and background of Western medicine in China during the last half-century. American influence in the development of Western medicine was particularly strong. The Rockefeller Foundation organized a China Medical Board in New York City in 1915 and supported the well-known Peking Union Medical College. During World War II, China owed much of its development of medical relief and educational work to the American Bureau for Medical Aid to China. A conference on the medical situation in 1946 was called by this organization with the aim of furthering the medical reconstruction of China after the war. Ambitious national health and medical education programs in the form of 5-, 10-, and 30-year plans were worked out in detail by the Chinese medical and health leaders (4).

\section{Medical Education in Communist China}

Owing to the shortage of physicians and other medical personnel, emphasis on medical educa- tion in the past 10 years has been on quantity rather than quality. It is claimed that during the last decade more than 40,000 graduates came out of medical and pharmacological schools. This number is nearly four times the total graduates from 1928 to 1947 . Graduates from secondary medical schools and secondary public health schools, which provide 2 to 3 years' training, numbered more than 153,000. Various auxiliary educational methods have been used to increase the training of such workers. In tune with the national policy that education should serve the working people, much political training was enforced in medical schools, perhaps to the point of being detrimental to scientific training.

It is a tremendous undertaking to train enough physicians and to establish enough hospitals to cope with the needs of a huge population like China's. A basis of only 1 doctor per 1,500 population requires 266,000 doctors for the 400 million population estimated before Communist rule. For a minimum of 5 hospital beds per 1,000 population, 2 million hospital beds would be required. With a population of 600 million today, as claimed by the Communist government, these numbers should be increased 30 percent. Even the United States is confronted with a shortage of physicians, and some top-grade medical schools have started new programs to shorten the training and reduce the cost of tuition. It is easy to understand why the Communists have preferred mass production rather than individual craftsmanship.

The quality of medical education has been little emphasized during this past 10 years. This has been a source of constant criticism by visitors to China and has promulgated the idea that the Communist government has sacrified quality for quantity. Some even see a danger of scientific retrogression (5). Although the idea of quantity versus quality is subject to argument, the fact remains that much progress has been achieved in preventive medicine and public health. The test of the validity of the criticism will be whether the government follows its original theme of mass production or, realizing the shortcomings, changes direction. The universally applied slogan in Communist China has been to do everything "by leaps and bounds and doing everything whole-heartedly, 
aiming higher with greater objectives to obtain quicker, better, and more economical results" (6).

In 1960 it was announced in the Chinese Medical Journal that a new college, China Medical College, has been established in Peking. It will offer an 8-year medical course instead of shortterm training. The curriculum consists of 3 years devoted to basic sciences, 2 years of basic medical knowledge, 2 years of clinical medicine, and 1 year of practical field experience. English and Russian are the compulsory languages. Many senior research specialists of the Chinese Academy of Medical Sciences and professors of the former Peking Union Medical College will be on the staff. The establishment of this new 8-year medical college is evidence of a realization of the importance of quality as well as quantity.

Among other examples are the achievements of the Chinese Medical Association. The association existed in Nanking 40 years ago; under the Communist regime it was moved to Peking. Membership increased from 4,000 in pre-Communist days to 18,472 by the end of 1958 . There are 16 professional societies within the association, and it has 54 branch associations throughout the country. Its activities have increased yearly, and many important national conferences have been sponsored jointly with the Ministry of Health.

At the association's headquarters, a five-story building in Peking built in 1957, is a sizable medical library. Publication of medical journals and books is also an important function; 25 major medical journals are now being issued, and more than 1,200,000 copies are circulated. It has been reported that 422 journals in 30 countries have exchange agreements with the association. Medical research has also been encouraged by the association and will be discussed later ( $(y)$.

\section{Integrating Traditional and Western Medicine}

To cope with the task that faced them, the Communists desperately needed medical manpower. One realistic way to accomplish this was to use the "traditional" Chinese physicians, reported to number about 370,000, throughout the country. These practitioners are not scientifically trained. They treat patients empir- ically using native herbs and drugs and healing methods based upon old Chinese medical theories. The modern Chinese physicians frowned on the methods of the traditionalists, and many difficulties ensued because of their objections. Yet the Communist government was determined to utilize these practitioners and the Vice-Minister of Health, Hsu Yun-Pei, reemphasized the need for "cooperation between traditional Chinese and Western medicine to promote people's health" (8). He stated, "The Chinese Commiunist Party has always advocated the unity of traditional Chinese medicine and Western medicine in order to fully develop the medical heritage and to advance medical science in China." Repeatedly emphasized was the long history of medicine in China, beginning with the Chinese Canon of Medicine (The Nei Ching) published in 200 B.C. Since then, several thousand volumes of Chinese medical writings have been handed down from generation to generation, thousands of Chinese herbs and drugs have been in use for several thousand years, and empirical physical treatments, such as acupuncture, moxibustion, massage, and breathing exercises have been widely practiced for centuries.

At the end of 1958 the Ministry of Health officially enforced the full-time study of Chinese traditional medicine by Western-trained Chinese physicians. By the end of 1959, 2,100 modern physicians were enrolled in 30 fulltime classes to study traditional medicine. In addition, many institutes and schools of traditional Chinese medicine were established to train new traditional practitioners who were simultaneously instructed in scientific medicine. In 1958, 3,200 such students were graduated. A department of traditional Chinese medicine has been established in most of the larger hospitals, and a considerable number of traditional physicians are on the staffs of county and commune hospitals. The integration of traditional medicine and Western medicine is growing stronger rather than weaker. Whether this will result in the deterioration of the quality of medical education in China remains to be seen.

\section{Practical Field Education}

Following the general educational policy of going to the countryside, all professional teach- 
ers and students must go to the rural areas and factories to work with the farmers and workers to gain practical field experience (9). In general, during every school calendar year, 38 weeks are earmarked for teaching, 6 weeks for vacation and holidays, and 8 weeks for practical fieldwork. The students and teachers must live and labor with their patients, eat the same food, and live the same lives. The Communist government feels that this field movement is the best way to make the medical workers serve the people so that productivity is promoted and the commune system strengthened. This step substantially corrected the concentration of medical personnel in the big cities, a phenomenon also common in most countries of the free world today. There is a question whether such compulsory regimentation of doctors will prove to serve the people better than our system of free doctor-patient choice.

\section{Publication of Medical Books and Journals}

Since 1953 all important medical books and journals have been published by the People's Medical Publishers in Peking. There are 77 different medical and health periodicals currently published throughout the country. The Chinese Medical Journal is issued monthly in Chinese and English editions. The monthly editions of the Chinese Journal of Internal Medicine and Chinese Journal of Surgery have English abstracts. The bimonthly Chinese Journal of Pediatrics, Chinese Journal of Ophthalmology, Chinese Journal of Dermatology, Chinese Journal of Radiology, and the Chinese Journal of Neurology and Psychiatry and the quarterly Chinese Journal of Pathology all print English abstracts. Two monthly English scientific publications, Scientia Sinica and Science Record, and eight different Acta Experimentali in Biologica Sinica are published quarterly by the Chinese Academy of Medical Sciences. The Central Research Institute of Health prepares the widely read monthly, People's Health, which was formerly part of the Chinese Medical Journal. The National Library of Medicine, Public Health Service, has a sizable collection of such periodicals available for reference.

\section{Progress in Medicine}

Improvement of sanitation and health education and prevention and control of common infectious and parasitic diseases have been reported $(6,8,10)$. It is claimed that public health and clinical medicine have caused the total disappearance of cholera in China and that plague and smallpox have been eradicated. Typhus, relapsing fever, and other "notifiable" or "reportable" infectious diseases have been brought under control.

\section{Infectious and Parasitic Diseases}

Great improvements have been made in the control of major parasitic diseases. At one time 10 million persons had schistosomiasis. It has been reported that 4 million of these have been cured, and many areas have been freed from such a disease. Various immunological tests have been developed and applied widely in the diagnosis of schistosomiasis. Among those reported are the intradermal reaction test with adult worm antigen or liver-ova antigen, complement fixation test, cercarial membrane reaction, circumoval precipitate reaction, and carmine flocculation reactions. A 3-day short course antimonial treatment has been widely used without increase of toxicity. The morbidity rate of schistosomiasis dwarfism is reported to be about 4 percent, and its clinical manifestations correspond to those of pituitary dwarfism. Ectopic schistosomiasis lung lesions are observed in more than 76 percent of acute cases and in 9.1 percent in late stages (11).

Millions of malaria patients have been treated, and the incidence rate has dropped to a level of less than 3 percent. A single dose of $0.4 \mathrm{gm}$. of quinacrine hydrochloride plus 0.04 gm. of plasmoquine given to 100,000 patients is reported to be both practical and effective. Other new Western antimalarial drugs and a native herb, Orixa japonica Thunb., have been utilized with good results (12).

Filariasis has been practically eradicated from 38 districts and municipalities and $2,600,000$ patients have been cured. A shortcourse treatment with a single dose of $1 \mathrm{gm}$. of diethylcarbamazine has been reported effective (1.3). The number of kala-azar patients has dropped from 530,000 to 10,000 within the last 
10 years. Hookworm infection (ancylostomiasis) is still widespread in the country. Reportedly, more than 36 million patients have been cured.

Knowledge of paragonimiasis as a systemic disease has been advanced, and the study of the pathology of this disease has proved that the pathway of the parasites to the brain is along the connective tissue around the blood vessels of the neck (14.15). Some comprehensive reports and abstracts from the All-China Conference on Parasitic Diseases were published in the January, February, and March 1959 issues of the Chinese Medical Journal.

As a result of the proper practice of personal hygiene and effective treatment, syphilis and gonorrhea are no longer menaces to health (16). An analysis of 103 cases of syphilitic juxtaarticular nodes between 1954 and 1958 indicated that such a condition is not rare in China (17).

Japanese B encephalitis has been studied extensively. Many strains of the virus have been isolated in various parts of China. Vectormosquitoes as well as hoofed animals are considered to be permanent hosts. Virus has been found in and successfully transmitted from mosquito ova. Under experimental conditions, Japanese B encephalitis virus lived in the body of hibernating mosquitoes for more than 164 days (18). Treating Japanese B encephalitis with traditional Chinese medicine has been claimed to be better than modern therapy (19).

Much research has been devoted to influenza in the past few years, especially after the 1957 epidemic. An All-China Influenza Conference was called, and one central and several regional influenza research laboratories were established in 1957. Many strains of virus were isolated and identified as Asian type $\mathbf{A}$ during that epidemic. According to available data, the epidemic appeared to have started at Yunnan-Kweichow border in southwestern China. Poliovirus, adenoviruses, and Coxsackie virus also have been isolated and studied.

\section{Cardiovascular and Renal Diseases}

The relative prevalence of rheumatic heart diseases is the highest ( 30 to 50 percent) of all organic cardiovascular diseases. Hyper- tensive heart disease ranks next, 20.1 to 20.3 percent, while arteriosclerotic heart disease constitutes only 4.6 to 15.5 percent (20). Investigation of population samples in Peking showed that the prevalence of hypertension was about 5 to 6 percent. A number of Chinese herbs and acupuncture therapy have been tried in the treatment of hypertension and reported to have had good effect.

A particular heart disease, "Keshan disease" $(y)$, reported in 20 percent of the people in an area with a population of 2,000 , was investigated. Clinically, this disease is similar to cardiac insufficiency or serious ventricular arrhythmia, and pathologically it has the signs of multiple foci of new and old myocardial infarction.

\section{Diseases of the Digestive System}

Infectious hepatitis has been the subject of much investigation. Material from a fairly extensive number of autopsies in Canton showed that postnecrotic cirrhosis constitutes 23.6 percent of the clinical cases of cirrhosis of the liver (21). Recently some preliminary success has been reported on the isolation of infectious hepatitis virus using chick embryo (18). For palliative treatment of ascites in cirrhosis of the liver, a combination of Western medical treatment and traditional Chinese medicine has reportedly kept many patients free from abdominal fluid for as long as 18 months (22). Cholecystitis and cholelithiasis have been seen frequently among younger age groups in China but show less sex ratio difference than in the U.S. The ratio between male and female is 1 to 1.2 (23). Even ascaris is commonly seen in the biliary tract, representing 10 to 45 percent of all surgical cases of biliary diseases (24).

\section{Diseases of the Respiratory System.}

Among the diseases of the respiratory system, pulmonary tuberculosis is still the most common, although the mortality rate has dropped rapidly. For example, in Peking tuberculosis mortality rates declined from 230 per 100,000 in 1949 to 46 per 100,000 in 1958 . Treatment by traditional Chinese medicine in combination with modern drugs has been tried extensively, 
reportedly with good results. Bronchial asthma has been treated with several herbal drugs (25).

\section{Endocrine and Metabolic Diseases}

Goiter is an important endemic disease in China. Surveys have been extensive and preventive measures have been taken. In addition to the deficiency of iodine in the diet, highcalcium and low-magnesium content in the drinking water from two endemic areas has been noticed (26).

A form of endemic deformative osteoarthritis called "big joint disease" has been reported in a number of northeastern and northwestern districts. It was believed to be Kaschin-Beck disease or Uroff disease. The etiology of this condition is still under study and a theory of dietary fungus intoxication has been suggested (27).

\section{Occupational Diseases}

Extensive medical and industrial health efforts have been devoted to checking widely prevalent silicosis, and the literature indicates considerable progress in diagnosis and treatment. Studies have been conducted to discover early neurological manifestations as a clue to early diagnosis. These include the disturbance of the ability to taste sweetness, functional deficit in the pain threshhold, and lowering of the protective inhibitions. Many cases of silicosis have been detected by these early signs before radiological examinations can be made (28).

\section{Surgery}

Progress in surgery has been rather slow. During the past 10 years China has concentrated on establishing surgical facilities in many hospitals. However, many surgeons have acquired considerable experience in modern surgical techniques. Anesthesiology has become a well-recognized specialty, and new techniques have been adopted. It has been reported that in a series of 1,785 cases of acute perforation of gastroduodenal ulcer, 38.2 percent were treated by gastric resection with a mortality rate of only 2.6 percent and an ulcer-recurring rate of 2.4 percent (29).

Acute pancreatitis is not rare in China and ranks fourth, after acute appendicitis, acute intestinal obstruction, and acute perforation, in frequency among abdominal surgical emergencies $(30,31)$.

Thoracic surgeons in China have made several modifications in the technique of thoracoplasty. A costoversion and refixation of two resected ribs in a cross form has been reported (32). Transpleural approach in radical treatment of tuberculosis of the thoracic spine has been reported to be effective and successful (33).

In a series of 100 cases of pulmonary resection of chronic lung abscesses, a vascular murmur was heard over the chest wall opposite the lung abscess in some of the cases. In subsequent pathological examinations the cause of the murmur was found to be the normal blood flow from the pulmonary vascular system through the dilated blood vessels in the pleural adhesions (34).

Progress in cardiovascular surgery, as well as cardiology, has been rapid. Operations such as mitral commissurotomy, pericardiectomy, and ligation of patent ductus arteriosus are practiced in most medical college hospitals and provincial hospitals. Direct vision intracardiac operations and transplantations with preserved or artificial blood vessels are performed in increasing frequency at a number of medical centers (35).

As a result of saving the life of one man whose severe burns covered 89.3 percent of his body surface, great enthusiasm has been engendered for improving the treatment of burns. Reportedly, many more lives have been saved by emphasizing proper management, restoring the balance of water and electrolytes, and preventing wound infection $(36,37)$.

\section{Pathology}

A detailed report on the progress in morphological pathology was published by $\mathrm{Hu}$ and Yang in the Chinese Medical Journal (38). They discussed the pathology of infectious hepatitis, tuberculosis, schistosomiasis, clonorchiasis, paragonimiasis, silicosis, and Keshan disease.

Liang at the Chung Shan Medical College in Canton (39) investigated the etiology and morphological pathology of primary liver carcinoma. He found that the occurrence of 
this condition among the Chinese, whether calculated on the basis of all autopsies performed (11.9 percent) or autopsies of those with cancer (26.2 percent), was more frequent than the respective occurrence for Europe and the United States. The Chinese develop primary liver carcinoma at an earlier age than do Europeans and Americans. The average age reported for the Chinese was between 30 and 49 years.

\section{Microbiology}

A comprehensive study on the etiology of trachoma by Tang and co-workers is of interest to microbiologists $(40)$. They report that virus is the likely etiological agent and that the transmission of this disease from human beings to rhesus monkeys by direct inoculation with conjunctival scrapings is possible. Also, the passage of infected materials in series was attempted. Further studies on the morphological changes of trachoma inclusion bodies under the influence of chlortetracycline, chloramphenicol, and streptomycin have been conducted by Yeh and Tang (41). In 1958 Tang and associates found the first strain of measles virus isolated in China (4R).

A hitherto undescribed virus latent in white mice was discovered by $\mathrm{Chu}$ and co-workers (43). Also, achievements in general virology and tissue culture have been attained by Kau Shan-Yin and associates (44). Recently many studies on streptomyces have been recorded, including serologic methods for their classification $(45)$.

Some progress also has been noticed in other fields such as neurology (46), obstetrics and gynecology (4\%), radiology (48), and otolaryngology (49).

\section{Traditional Chinese Medicine}

Traditional Chinese medicine is an empirical healing art based on 4,000 years of practical experience. Its theory of disease is simple and medieval. Its concept of health and disease is the functional bodily harmony or disharmony between two forces, yin (the negative) and yang (the positive). Anatomically and physiologically, traditional Chinese medicine has practically nothing to offer, yet the vast volumes of herbs and drugs and the medical treatises recording observations of diseases are precious. The results of treatment with these drugs and the healing art of acupuncture, moxibustion, massage, and breathing therapy have an empirical value. Discussion of Chinese herbs and drugs is in the realm of pharmacology, and only acupuncture, which is a controversial subject, will be discussed here.

Acupuncture, a healing art peculiar to China, was practiced as early as 200 B.C. (50). It consists of the introduction of hot and cold needles into the body at specific points. The needles may be fine or coarse, short or long (3 to $24 \mathrm{~cm}$.).

Application is based upon the old Chinese medical theory that internal organs and various parts of the body are intimately related and work in harmony for the maintenance of health. These organs and body parts are hypothetically connected by 12 channels (Ching). When the needles puncture and stimulate different tissues or organs at various depths, they cause physiological reactions and thus produce healing results. Practicing acupuncture in ancient times was dangerous owing to ignorance of aseptic techniques and the lack of anatomical knowledge.

Acupuncture was carried from China to Japan at an early period but was not introduced to Europe until later. At one time it created considerable interest in Europe, especially in France. François de Remusat published a long analysis for and against this practice at the beginning of the last century. Later Sir James Cantlie tried it successfully in several cases of rheumatism and sprains. Morant and Ferroyrolles contributed a review of its history and application (50).

In 1956 the Russians sent a group of physicians to Peking to study the art of acupuncture. At present intensive studies on the unknown mechanism of acupuncture are being conducted in Moscow by Soviet and Chinese physicians. The hypothesis is that stimulation from punctures is conducted from the peripheral nerves to the brain cortex and suppresses the pathological irritation in the brain. Such explanation seems to be in harmony with the Pavlov theory of conditioned reflex.

Acupuncture has been widely used for prac- 
tically all kinds of diseases ranging from surgical conditions such as appendicitis to chronic conditions such as diabetes. It is believed that it produces best results in illnesses of the nervous system or those of neurological origin. Good results have been reported in the treatment of facial paralysis, arthritis, eczema, and other conditions.

One Russian physician reported that his long painful arthritis was much improved by acupuncture (51). A physician from India who studied acupuncture in China in 1958 entertained certain doubts as to its value at first. However, he later believed that the integration of traditional medicine and Western medicine had already accomplished remarkable successes. He was also treated successfully by acupuncture for acute sinusitis (52).

Dr. Wu Lien-Teh, the great plague fighter (53) during the severe Manchurian epidemic half a century ago, said in the preface to "History of Chinese Medicine" (50) that "Chinese medicine, to be understood and its significance appreciated, must be studied as a whole. In no other field of endeavor in this country has the experimental method realized such concrete and far-reaching results as in the domain of medicine."

Whether the Communists will succeed in their ambitious endeavor to produce a new Chinese medical science by incorporating traditional medicine with modern scientific medicine only time can tell. Whatever the outcome, this development is worthy of constant attention.

\section{Preventive Medicine and Sanitation}

Most visitors have noticed that China has achieved great successes in preventive medicine and sanitation in stamping out many major infectious and parasitic diseases during the past 10 years. This resulted, for example, in the decline of the general mortality rate in Peking from 14.1 to 7.4 per 1,000 during this period.

The first step was a campaign to eliminate the four major pests, mosquitoes, flies, rats, and grain-eating sparrows. They integrated public health with mass action by what was called the "patriotic health movement." Throughout the country millions of people, including the aged and the very young as well as the workers, were mobilized to kill the four pests. They used all available antivermin chemicals and devices, swatted mosquitoes and flies with their hands, and threw sticks and stones at rats and sparrows.

Reportedly, more than a billion sparrows, $11 / 2$ billion rats, 100 million kilograms of flies, and 11 million kilograms of mosquitoes were eliminated in 1959. It was humorously reported that many sparrows, constantly chased by the people hour after hour, finally died of sheer exhaustion. Many visitors today are surprised that these pests have practically disappeared from China.

It must be pointed out that such concerted mass action was possible through effective enforcement of police power and the voluntary cooperation of the people. In such campaigns, families in each block or ward in a city formed their own groups and elected a group leader for the street committee. Under the chairmanship of a member from the local district council, the street committee served as the basic unit in carrying out the government orders concerning public health and other matters, such as education, welfare, security, and arbitration between neighbors. The committee chairman also represented the voice of the people to the government. The two-way public representation was believed to be the real reason for the success of this battle (5).

The improvement of general environmental sanitation and the practice of personal hygiene, both in the cities and the rural areas, is also phenomenal. Swampy parts of rivers and streams have been drained and irrigation improved. Countless old refuse dumps and stagnant pools have been transformed into parks and recreational areas throughout the country. China is also reconstructing slums. Much attention is being given to research on various public health problems ranging from the disinfection of well water and the washing and cooking of vegetables to the effect of heat on factory workers and climatic influence on infant mortality $(54)$.

\section{Philosophy of Medical Care}

The practice of medical care in China today may be said to be a modification of the social- 
ized medicine of the Soviet Union. However, patients do pay small fees to hospitals, clinics, or health centers. Usually very small fees are charged for physicians' services and more substantial ones for expensive drugs, $\mathbf{X}$-rays, and surgery. The trend, already apparent among the so-called "privileged groups" in most cities, is to provide more hospitals and clinics in order to give more free medical care to the people. China is reported to have 300,000 hospitals and clinics with more than 400,000 hospital beds and 1,400 anti-epidemic stations. Recently it has been claimed that 700,000 industrial workers, 360,000 teachers, and university students and government workers in Peking alone are receiving free medical services. In Shanghai the same privilege has been given to $1,160,000$ workers, 280,000 teachers, and students and government workers. More than 1 million dependents of factory workers pay only half of their medical expenses.

Obviously physicians in China do not have freedom of medical practice. All physicians, nurses, technicians, sanitarians, and other health workers are government employees and are paid set salaries by the hospitals or health agencies. Although private practice still exists in some big cities, the scope is negligible. Government regulations restricting fees make it impossible for practitioners to earn greater incomes than the government salaries.

In various city and country resorts hundreds of sanitariums are now available free of charge for privileged groups (55).

\section{Three-Level System}

The medical care system is divided into threo levels (5). The primary level of medical care consists of the municipal clinics in cities and the county health centers in rural areas. $\mathrm{Pa}$ tients are seen by modern medical or traditional physicians for general diagnoses and primary treatment during three 8-hour shifts. When physicians are not immediately available for house calls, nursing aides or health aides administer emergency first aid in the villages.

At the secondary level, medical care is given at better staffed and better equipped county or district hospitals. These hospitals have a bed capacity of between 200 to 300 to handle specific medical or surgical cases.
The third level of medical care consists of highly specialized hospitals or health institutions operated by large municipalities, provincial governments, or medical colleges, similar to big medical centers in the United States. The general public health responsibility at this level rests with the health departments of the Provinces or special municipalities. These agencies are under the direction of the Ministry of Health of the Central Government.

\section{Medical Care in a People's Commune}

The Communists believe in a commune system that is an integrated organization of workers, farmers, merchants, students, and soldiers. These people are organized into militia to meet any military emergency and into production brigades to attain the quota set for national reconstruction. Within the commune system are medical and health installations, mess halls, kindergartens, nurseries, gynecologic and obstetric hospitals, and institutes for the reverence of the aged. The Communists are determined to convert by force if necessary their ideal of a commune system into total socialization.

To see the trends in the medical care system in China, it will be helpful to consider an example of a typical people's commune (56). In the rather hilly countryside of north China, is Mee Hsien, a county which has recently developed into a prosperous coal-mining area with various small industries. It is composed of seven communes of various sizes. One commune has a population of 40,121 divided into 17 production brigades. Each production brigade is subdivided into 4 to 10 production regiments in the various villages.

Each people's commune has a managing council which controls all production brigades and supervises the medical and health agencies. These agencies include a commune health center clinic with several health stations, obstetric clinics, and many health aides, nursing aides, and obstetric aides (see chart).

The commune health center clinic has a staff of 43, 9 modern and 7 traditional physicians, 10 nurses, 11 technicians, 3 administrators, 2 public health personnel, and 1 maternal care nurse. There are 25 hospital beds at the clinic, a ratio of 0.6 beds per 1,000 population. 
Each of the 17 production brigades in the commune has a health station. The health station is under the administrative direction of the commanding officer of the brigade, with the director of the health center clinic having only technical responsibility. There are 3 or 4 modern or traditional physicians at each station. They serve an area with a 3 - to 4 -mile radius covering 8 to 10 villages, provide outpatient care at the station, and make emergency house visits.

One nurse at each health center clinic is responsible for maternal and child health within the commune system. Each production brigade has one obstetric clinic with an experienced obstetric aide to assist the physicians. At present it is claimed that 60 percent of all infants are delivered by scientific methods. In the larger cities this number is reported to be as high as 98 percent $(5 \%)$.

The need for nurseries and kindergartens ilepends upon the seasonal employment of mothers. Usually, during busy seasons of the year, many temporary nurseries are established. Each production regiment has its own health aides, nursing aides, and obstetric aides working under the supervision of the doctors and nurses.

All patients are charged nominal medical fees at the health center clinic which is supported by the whole commune. Charges for services given by the health stations vary with the productivity of the production brigades. Usually the patients pay 30 to 50 percent of the cost of medicines.

The medical organization in a commune is analogous to a basic unit in an army medical corps. However, with the shortage of medical personnel and the inadequacy of medical facilities, it appears that a socialized medical system is still far from successful.

\section{Central Research Institute of Health}

In 1950 the former Central Health Experimental Institute in Nanking was reorganized into the Central Research Institute of Health and moved to Peking (58). Devoted to research directly or indirectly related to people's health, it consists of six departments: microbiology, sanitary engineering, nutrition, pathology, pharmacology, and Chinese herbs.

\section{Basic medical and health organizations of a people's commune}

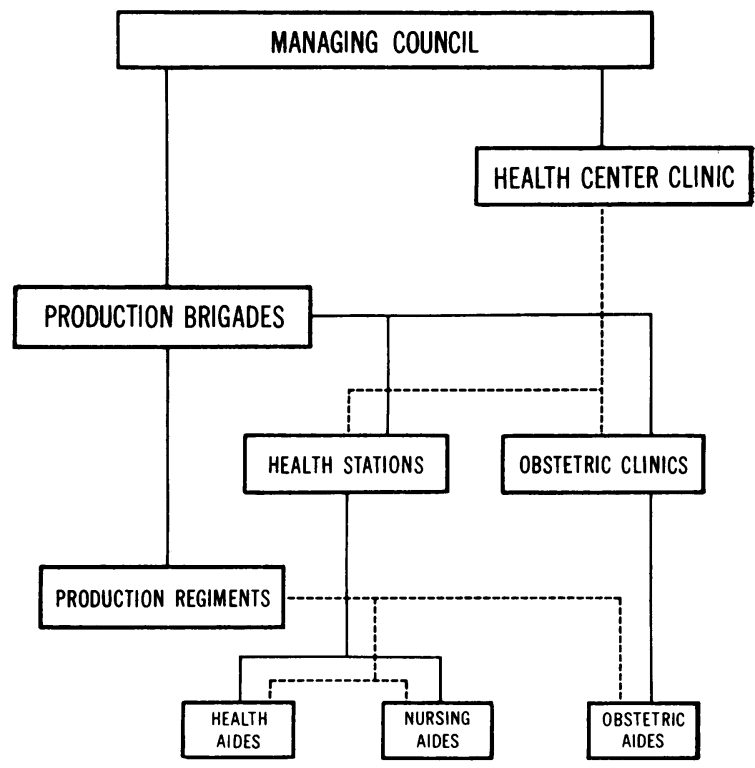

Its branch institute in Nanking investigates parasitic diseases and a branch institute in Hainan Island studies malaria. Currently there is a staff of more than 250 scientific research workers.

The department of sanitary engineering is concentrating on problems of general sanitation and industrial ventilation and cooling. Many experiments have been conducted using natural raw materials as a source of insecticides such as DD'T and 666. Investigations of various parasitic and infectious diseases, such as schistosomiasis and malaria, conducted or sponsored by the institute, have already been mentioned. The nutritional value, especially vitamin content, of wild vegetables and the potentialities of beans, rice, and other foodstuffs as milk substitutes have been studied intensively. Much pharmacological research has been devoted to synthetic production of native antimalarial and antituberculosis drugs. Recently the study of physiques has caught the interest of the institute staff in their efforts to promote better physical health and thus aid national defense and production.

\section{Cancer Prevention and Control}

The Communists have also realized the importance of preventing and controlling chronic 
diseases. Recently they launched a vigorous cancer campaign (59). Although achievements in cancer research have not been of great significance, the scope of this disease in such a vast population warrants attention. Mass detection of cancer, especially of the uterus and cervix, esophagus, and nasopharyngeal cavity, was started in 1958, and more than 4 million people have been examined in 13 Provinces and cities.

Cancer of the cervix was most frequent: 90.8 percent of all cancer detected in Shanghai. Cancer of the esophagus was more prevalent in northern China than elsewhere, while cancer of the nasopharyngeal cavity was higher in the south (60). A detailed analysis revealed that the incidence rate for cancer of the esophagus among 3,100,000 persons surveyed in northern China in 1959 was 18.3 per 100,000 and the mortality rate was 16.2 per $100,000(61)$. The Department of Pathology, Chinese Academy of Medical Sciences, has also made a statistical analysis of 13,779 surgical specimens seen during the last 40 years. The data showed that the percentage of esophageal cancer was 4.7 percent (62).

The Chinese have studied cancer of the liver intensively. Thirty-eight medical colleges reviewed 21,706 autopsies from January 1950 to June 1957 and found 1,979 tumors diagnosed as malignant. Liver cancer comprised 1.2 percent of all autopsies and 26.4 percent of all cancers (63).

In areas of northern China such as the Canton district, malignant cholangioma was considered probably related to the infection with clonorchiasis. In 200 cases of primary carcinoma of the liver, 46 were reportedly complicated by this infection with various stages of epithelial hyperplasia in the secondary intrahepatic ducts up to the development of cancer (64).

Bronchogenic carcinoma was reported to be 18.4 percent of all tumors found in autopsies. Some investigation on lung cancer-cigarette relationship has been conducted and led to the belief that cigarette smoking is not the only etiological factor. A high percentage of lung cancer occurred in permanent rural residents $(65,66)$.

Among the tumors of the genitourinary sys- tem, it was reported that, out of 27,149 cases of cancer studied, 4.6 percent occurred in the urinary system and male genital organs. Cancer of the bladder was found in 1.3 percent of 987 cancer autopsies. However, prostate cancer among the Chinese was reported to be rare. Among 28,884 cases of malignant tumors studied in Shanghai, only 16 were prostate cancer $\left(6^{\prime \prime}\right)$.

\section{Medicine and Public Health in Taiwan}

Although this is a report on Communist China, the accomplishments of the Chinese scientists in Taiwan or Formosa should also be mentioned. There are today more than 4,000 qualified physicians, 700 dentists, and 700 pharmacists registered in that tiny island with a population of a little more than 10 million and a total area of about 14,000 square miles. Many are migrants from the mainland.

They are conducting an excellent county health center system which was begun by the Nationalist Chinese Government when it moved to Formosa. At the present time, there are three medical schools on the island. They not only produce a sizable number of medical personnel but engage in various kinds of research, including study of diseases of obscure etiology and diseases among the aborigines. In cooperation with American universities and medical institutions, research activities have increased during the last few years (68).

\section{Conclusion}

In reviewing the progress of medicine and public health in China today, one of the most startling accomplishments is the prevention and control of many infectious and parasitic diseases which had ravaged that country for generations. The improvement of medical education in quantity, if not quality, has also been noted. However, other progress in medicine is not actually as rosy as the Communists' propaganda indicates.

The integration of traditional Chinese medicine with Western medicine is obviously being overdone, but at present no one is in a position to conclude that nothing of value or importance to medical science will result. 
There is a great socioeconomic revolution going on in China among one-fourth of the world's population. No matter what the political outcome, the impact of this revolution on the philosophy and practice of medicine and public health should not pass unnoticed by the rest of the world. Although the enforcement of the commune system has met with much opposition inside China and received severe criticism abroad, its success or failure will naturally depend upon the benefits reaped by the people, including medical care. Since medical care for the aged is one of the urgent needs in the United States today, it should be no surprise that even the Communists are trying to find a solution.

It should be remembered that most senior physicians and medical scientists in Communist China today are either American-trained or have visited the United States on an exchange basis. For the most part, they are competent workers and thinkers and form the backbone of that Nation's medical service. They have great admiration for the advances and contributions of the United States to medical science.

\section{REFERENCES}

(1) Sze, S.: China's health problems. Chinese Medical Association, Washington, D.C., 1944.

(2) Lim, R. K. S., and Chen, C. C.: State medicine. Chinese M. J. 51: 781-796, June 1937.

(3) Grant, J. B.: Western medicine in pre-Communist China. Am. J. Pub. Health 50: 36-39, June 1960, pt. 2.

(4) American College of Physicians and Surgeons: Proceedings of the Conference on the Present Medical Situation in China, June 15, 1946. American Bureau for Medical Aid to China, Inc., New York.

(5) Fox, T. F.: Medical care in Communist China today. Am. J. Pub. Health 50: 28-35, June 1960, pt. 2.

(6) Li, T. C.: Ten years of public health work in China. Chinese M.J. 79: 483-488, December 1959.

(y) Fu, L. C.: Achievements of the [Chinese Medical] Association in the past ten years. Chinese M.J. 79: 208-218, September-October 1959.

(8) Hsu, Y. P.: Cooperation between traditional Chinese and Western medicine to promote people's health. Chinese M.J. 79: 489-492, December 1959.

(9) Tsui, Y. T. : Chinese M.J. 80 : 1-3, Jan. 25, 1960.
(10) Hou, T. C., et al.: Achievements in the fight against parasitic diseases in New China. Chinese M.J. 79: 493-520, December 1959.

(11) Chi'en, H. C.: Summing up of mass technical experiences with a view to expediting eradication of the five major parasitic diseases. Chinese M.J. 77 : 521-532, December 1958.

(12) Chi'en, H. C.: People's Health 1: 3 (1959).

(13) Chiu, Y. C., et al.: Chinese J. Int. Med. 4: 940 (1956).

(14) Lin, C. K., et al.: Chinese J. Int. Med. 2: 254 (1954).

(15) Lei, H. H., et al.: Nat. M. J. China 41: 166 (1955).

(16) Progress in internal medicine in New China. Chinese M.J. 79 : 219-252. September-October, 1959.

(17) Li, H. C., et al.: Syphilitic juxta-articular nodes : Analyses of 103 cases. Chinese M.J. 79: 348353, September-October 1959.

(18) Chinese Medical Association: Proceedings of AllChina Conference on Acute Infectious Diseases. Peking, May 1959.

(19) Chou, H. C. : Epidemic type B encephalitis. Chinese M.J. 80 : 548-553, June 1960.

(20) Tung, C. L., et al.: Chinese J. Int. Med. $7: 109$ (1959).

(21) Liang, P. C. : Nat. M.J. China 42: 801 (1956).

(22) Chiang, C. H., et al.: Chinese J. Int. Med. 44 : 659 (1958).

(23) Chang, C. L. : Chinese J. Surg. 4 : 251 (1956).

(24) Fei, Y. C., et. al.: Chinese J. Surg. 6 : 1029 (1958).

(25) Pang, C. Y.: Peking Traditional Chinese Med. 3 (11) : 29 (1954).

(26) Han, S. C., et al.: Shansi M. J. $2(4)$ : 10 (1958).

(27) Kuo, Y. P.: Monograph of Kaschin-Beck disease. Ministry of Health, Peking, 1956.

(28) Kuo, Y. P., and Liu, Y. T.: Silicosis. Chinese M.J. 79 : 326-335 (1959)

(29) Chen, T. Y., et al.: Chinese J. Surg. $4: 134$ (1956).

(30) Wu, M. N., et. al.: Chinese J. Int. Med. 4: 675 (1956).

(31) Cheng, T. T.: Chinese J. Int. Med. 7 : 40 (1959).

(32) Liang, C. S., et al.: Chinese J. Tuberc. 3 : 162 (1955).

(33) Fan, P. C., et al. : Transpleural approach in radical treatment of tuberculosis of thoracic spine. Chinese M.J. 79: 284-289, September-October 1959.

(34) Wu, Y. K., et al. : Chinese J. Surg. 5 : 358 (1957).

(35) Wu, Y. K.: Recent progress in cardiovascular surgery in China. Chinese M.J. $80: 415-416$, May 1960.

(36) Shanghai Second Medical College, Kwang Tse Hospital, Burn Treatment Unit: First report on burn treatment. Chinese M.J. 78: 4-11, January 1959.

(37) Shanghai Second Medical College, Kwang Tse Hospital, Burn Treatment Unit: Second report on burn treatment. Chinese M.J. 78: 240-256, March 1959. 
(38) Hu, C. H., and Yang, C.: A decade of progress in morphologic pathology. Chinese M.J. 79 : 409 422, November 1959.

(39) Liang, P. C., et al.: Morphologic study and etiology of primary liver carcinoma and its incidence in China. Chinese J. Path. 5 : 161 (1959).

(40) Tang, F. F., et al.: Studies on the etiology of trachoma. Parts 1 and 2. Acta Microbiol. Sinica 6(1) : 1-13 (1956).

(41) Yeh, C. F., and Tang, F. F.: Studies on the morphological changes of trachoma inclusion bodies under the influence of aureomycin, chloromycetin and streptomycin. Acta Microbiol. Sinica 6(2) : 203-207 (1958).

(42) Tang, F. F., et al.: Studies on the etiology of measles with special reference to isolation of virus. Scientia Sinica 7 (7) : 758-767 (1958).

(43) Chu, C. M., et al. : A study on a new mouse virus. Acta Microbiol. Sinica 4 (1) : 33-46 (1956).

(44) Kau, S. Y., et al.: Virology and tissue culture. Wuhan University Natural Science Bulletin No. 3, 1959.

(45) Liang, S. F., et al.: Serological methods as an aid to the classification of streptomyces species. Scientia Sinica 7 (8) : 844-852 (1959).

(46) Feng, Y. K. : Neurology in New China. Chinese M.J. 79 : 398-408, November 1959.

(47) Lim, K.: Obstetrics and gynecology in the past ten years. Chinese M.J. 79 : 375-383, November 1959.

(48) Wang, S. H., and Liu, K. N.: Present status of roentgenology in the diagnoses of paragonimiasis. Chinese M.J. 79 : 446-455, November 1959.

(49) Chinese Journal of Otorhinolaryngology Editorial Board: Otolaryngology in China since liberation. Chinese M.J. 79: 423-427, November 1959.

(50) Wong, K. C., and Wu, L. T.: History of Chinese medicine. Ed. 2. Mercury Press, Shanghai, 1956, pp. 227-232.

(51) Journal of Traditional Medicine in Kiangsi Province, December 1958.

(52) Basu, B. K.: My impression of acupuncture and moxibustion. Chinese M.J. 78: 580-581, June 1959.
(53) Wu, L. T. : Plague fighter. W. Heffer and Sons, Ltd., Cambridge, England, 1959.

(54) Yang, C. P.: The influence of winter upon the mortality rate of infants in Harbin. People's Health 11: 1003-1066, November 1959.

(55) News and notes: Chinese M. J. 7 : 568-570, December 1959.

(56) Honan Medical College, Department of Public Health: A survey of the basic organization of medical care in the people's commune system, Mee Hsien, Honan. People's Health 2: 219 222, April 1960.

(57) Li, S.: Maternity and child welfare in people's commune. Chinese M.J. 78: 576-579, June 1959.

(58) Shen, C. C.: Chinese M.J. 57: 680-698, July 1956.

(59) Chien, S. C.: Prevention and research of cancer. Chinese M.J. 80 : 8-14, January 1960.

(60) Yu, A. F., and Ko, Y. K.: Chinese M.J. 80 : 21-27, January 1960.

(61) Peking Union Hospital and Peking Obstetric and Gynecologic Hospital, Department of Obstetrics and Gynecology: Chinese M.J. 80: 459-465, May 1960.

(62) Chinese Academy of Medical Sciences: Youth anticancer shock brigade. Chinese J. Path. 4: 258 (1958).

(63) Yeh, T. F.: Chinese M.J. 79: 338-540, December 1959.

(64) Hou, P. C.: Chinese J. Path. \& Bact. 72: 239 (1956).

(65) Shih, M. H., et al.: Chinese J. Tuberc. $7: 87$ (1959).

(66) Chu, K. C., et al.: Chinese J. Tuberc. 7: 92 (1959).

(6y) Shanghai First Medical College, Department of Pathology: Report on autopsy review. Chinese J. Path. 5: 77 (1959).

(68) Wei, H.: Medical education and research in the Republic of China. Report to the Sino-American Conference on Intellectual Cooperation at the University of Washington in Seattle, July 9-15, 1960. Mimeographed. 